\title{
LA CLIMATOLOGÍA Y EL NEGOCIO DE LA SAL EN LA IBIZA DEL SIGLO XVII
}

\author{
ANTONIO EsPino LóPEZ \\ Universidad Autónoma de Barcelona
}

Fecha de recepción: enero 2015

Fecha de aceptación: marzo 2015

Una de las peculiaridades de la isla de Ibiza en las edades Media y Moderna fue su extraordinaria dependencia económica de sus salinas. Sin apenas otro producto que exportar, los ibicencos estaban sujetos de manera notable a las oscilaciones del comercio internacional de la sal. Sin duda, la situación geográfica de la isla, en la encrucijada de numerosas vías marítimas, ayudó a ello. Ibiza abasteció de sal a Génova (a partir de 1258), Florencia, Milán, Nápoles, Sicilia, Ancona, Venecia, pero también al norte de África y a la Europa atlántica ${ }^{1}$ merced a los servicios de mallorquines, catalanes, valencianos, vascos, raguseos o flamencos tras la conquista cristiana de 1235 .

Pero en el transcurso del siglo XVI, la sal ibicenca perdió competitividad, sobre todo en los mercados italianos controlados por Venecia ${ }^{2}$. La crisis fue dura en Ibiza, cuya producción se volcaba en abastecer los puertos italianos. A decir de J.-Cl. Hocquet, «[...] en 1598, les habitants avaient abandonné el estaño de la sal et manquaient d'argent pour fortifier les tours contre les pirates barbaresques. L'aggravation de la piraterie décourageait partout les citoyens les plus riches de tenter, comme par le passé, l'aventure de l'armement et du commerce maritimes» ${ }^{3}$.

1. Hocquet, J.-Cl., «Ibiza, encrucijada del comercio marítimo y testigo de una coyuntura mediterránea (1250-1650 aproximadamente)», en VV. AA., Comercio marítimo en el Mediterráneo medieval y moderno. Granada: Universidad, 2002, pp. 19-91, esp. pp. 53-54.

2. Escandell, B., Ibiza y Formentera en la Corona de Aragón. Tomo II, (Siglos XIV-XVI) De la crisis medieval a la Ibiza renacentista. Palma de Mallorca: L1. Muntaner, 1995, pp. 596-600.

3. Hocquet, J.-Cl., Le sel et la fortune de Venise. Vol. II, Voiliers et commerce en Méditerranée, 1200-1650. Lille: PUL, 1979, p. 685. «[...] en 1598, los habitantes habían abandonado el estaño de la sal y faltaban dineros como para fortificar las torres [defensivas] contra los piratas berberiscos. El agravamiento de la 
En cambio, entre 1600 y 1624, la sal ibicenca ganó mercado en Génova y, sobre todo, en Niza y Marsella, y las importaciones ibicencas oscilaron entre 30.000 y 40.000 minas $^{4}$ genovesas (38.055 en 1628). En 1655, por ejemplo, se recuperó notablemente la producción, vendiéndose 3.000 modines en Mallorca, Menorca y Cataluña y nada menos que 20.000 a diversos destinos italianos, pero lo cierto es que en la segunda mitad del siglo XVII, el único cliente importante que quedaba para la sal ibicenca eran los genoveses 5 .

La sal, pues, tenía una función primordial en la economía de la isla: era la principal fuente generadora de renta, el elemento esencial de la política impositiva, y, a menudo, se utilizó como moneda de cambio o un medio apropiado para realizar los pagos debidos a cuenta de las vituallas adquiridas por los habitantes de la isla. Un gobernador de Ibiza también acabó siendo, hasta cierto punto, el administrador último de dicha fuente de riqueza en pugna con los jurados de la isla 6 .

La principal dificultad para la vida en la mayor de las Pitiusas eran las recurrentes malas cosechas que obligaban a sus habitantes a depender de las importaciones de granos (pagadas normalmente con sal). Quizá, quien explicara mejor aquellas circunstancias fuese el pavorde Mariano Castany, síndico de la isla en la corte, en 1662:

la isla es de sí tan estéril, que poquissimos años produce suficientes frutos para su necesario sustento, de tal manera que la mayor parte del tiempo han de comer pan de cebada [...] Muchos labradores no le tienen aún, ni medios para conseguirlo, y se valen de algarrobas, que faltan también. A otros aún les falta este consuelo, pues se sustentan con piñoncillos tostados, de las piñas más silvestres, que comen con hueso y todo, por ser el me $<\mathrm{h}>$ ollo de ellos casi imperceptible. Otros hazen grandes ollas de yerbas del campo, cozidas sin azeyte: de todo lo qual se ocasiona no pocas enfermedades. A otros los hallan muertos, sin haverles conocido más enfermedad que su miseria.

Y una interesante mirada a la meteorología: Castany hacía observar que, en el caso de Ibiza, los años de escasas lluvias la cosecha de grano sería ruinosa, pero no así la de la sal, que necesitaba reducidas precipitaciones desde la primavera para que la sal «cuajara». Por otro lado, una lluvia excesiva podía llegar a arruinar los estanques de la sal, pues no sólo los anegaba, sino que los llenaba de lodos. Así, simplificando un tanto, el año que había grano no había sal, y viceversa ${ }^{7}$.

piratería descorazonaba a los habitantes más ricos a emprender, como en el pasado, la aventura de armarse y del comercio marítimos»».

4. En el siglo XV, la mina genovesa equivalía a $130 \mathrm{kgr}$.

5. Hocquet, J.-Cl., Le sel et la fortune de Venise. Vol. I, Production et monopole. Lille: PUL, 1978, pp. 133, 207-208, 318. Hocquet, J.-Cl., Le sel et la fortune de Venise, vol. II, pp. 129, 160-161, 317, 320323. HocQUeT, J.-Cl., «Ibiza, encrucijada del comercio marítimo y testigo de una coyuntura mediterránea (1250-1650 aproximadamente)», pp. 41-42, 80-81, 85-91.

6. Escandell, B., Ibiza y Formentera en la Corona de Aragón. Tomo III/1. De la crisis barroca a la planificación ilustrada (siglo XVII). Oviedo: Universidad, 2000, pp. 388 y ss. Asimismo, Vila Valentí, J., «Ibiza y Formentera, islas de la sal (1953)», en Territoris. Revista del Departament de Ciències de la Terra, n. ${ }^{\circ}$ 3, Palma de Mallorca, 2001, pp. 117-156.

7. Biblioteca Nacional (BN), Varios Especiales (VE), 25-63, «Señor, el doctor y paborde Mariano Castany, syndico de la isla de Ibiza [...]», 1662. 
Nuestro principal interés en el presente trabajo será, pues, analizar el difícil equilibrio que se debía alcanzar en Ibiza entre el suministro de granos para una población de entre 9.000 y 10.000 habitantes cuando fallaban las cosechas, la venta de sal en las mejores circunstancias posibles para cubrir dicho déficit, así como las condiciones de explotación de los estanques y las dificultades meteorológicas que podían acabar por arruinar la cosecha de la sal (y poner en peligro la economía de la isla).

\section{DIFICULTADES FRUMENTARIAS E IMPORTACIÓN DE GRANOS}

En la siguiente tabla consignamos los datos recabados acerca de las importaciones de granos $^{8}$ en la isla en el transcurso del siglo XVII.

\section{Tabla 1. Importaciones de granos, Ibiza siglo XVII}

\begin{tabular}{|c|l|}
\hline Año & \multicolumn{1}{|c|}{ Cantidades importadas } \\
\hline 1605 & 6.000 cuarteras de trigo \\
\hline 1611 & 4.000 cuarteras de trigo \\
\hline 1627 & 4.000 fanegas de trigo y 2.000 de cebada \\
\hline 1631 & 6.000 cuarteras de trigo \\
\hline 1641 & 4.000 cuarteras de trigo \\
\hline 1646 & 3.000 fanegas de trigo \\
\hline 1647 & 12.000 fanegas de trigo \\
\hline 1652 & $4.000-5.000$ cuarteras de trigo \\
\hline 1661 & ¿11.000 cuarteras de cereales? \\
\hline 1665 & 2.000 cuarteras de trigo \\
\hline 1671 & 10.000 fanegas de trigo \\
\hline 1674 & 4.000 cuarteras de trigo \\
\hline 1687 & 3.000 cuarteras de trigo \\
\hline 1688 & 3.000 cuarteras de trigo \\
\hline 1699 & 3.000 cuarteras de trigo \\
\hline 1700 & 3.000 cuarteras de trigo \\
\hline
\end{tabular}

Fuente: ACA, CA, legs. 1031 a 1048. Elaboración propia.

Nota: la cuartera equivale a 70 litros y la fanega a 55,5 litros.

8. También hizo falta importar granos en el reino de Valencia a causa de la sequía (la hubo en 1625-1628, 1631, 1635, 1637, 1645 y 1650): en concreto, desde Mallorca se enviaron 483 cahíces de grano entre 1626 y 1650 y desde Menorca 50. Al respecto, BlANEs ANDRÉs, R., «Comercio de importación marítima de cereales en la Valencia del segundo cuarto del Seiscientos», en F. J. Aranda (de.), La declinación de la Monarquía Hispánica en el siglo XVII. Cuenca: Universidad de Castilla-La Mancha, 2004, pp. 481-499, esp. pp. 492 y 496. 
Como se puede observar, si bien se podrían incluir cifras inferiores para casi cada año del Seiscientos, en determinados momentos el volumen alcanzado por las necesidades de grano fue notorio, y lo sería aún más de incluir el resto de vituallas que se debían importar. Por ello era tan crucial disponer de sal suficiente para trocarla por los bastimentos necesarios. Como explicaba el gobernador Joan de Castellví en 1634:

Primeramente se ha de presuponer que esta isla no se puede proveer de vituallas si no es con sal porque la moneda usual de aquí no corre en otra parte y los que vienen a cargar casi todos vienen con vituallas como son trigo, arroz, aceite, carnes y legumbres. De todo lo cual casi todos los años necesita esta isla porque en moneda de plata son muy caros los navíos que vienen a cargar y si acaso llega alguno se irá primero vacío sin cargar que pagar la sal por su justo valor, que son 35 reales sin el derecho nuevo [otros 12 reales]. De manera que todo el trato y conservación de esta isla consiste en trocar sal con vituallas, porque no haciéndose así de todo punto se habría de desamparar la isla $[\ldots]^{9}$.

Uno de los problemas con los que habría que enfrentarse a menudo era la falta de honradez de aquellos que mercadeaban con dichos productos, quienes se aprovechaban de las circunstancias y vendían «la cuartera de trigo a 40, 50 y a 60 reales de plata, el quintal de arroz a 60,70 y a 80 [...] y el cántaro de aceite a 36 y a 50 y más reales [...]», decía el gobernador F. Miguel en $1654^{10}$.

En otras ocasiones, como en 1636, era la guerra -y el casi cese de los fletes de barcos- la que dificultaba la llegada de algunos productos de primera necesidad, aunque la cosecha de grano hubiese sido buena, pues también se necesitaba en Ibiza carne, arroz, atún, aceite y legumbres ${ }^{11}$. En otro año de guerra, 1641, se fueron a buscar cien carneros a la Península para los enfermos, aceite a Mallorca y de Italia algo más de cuatro mil fanegas de trigo «que faltarán este año, y todo se paga con sal, y el año que no se puede sacar de los estaños no hay sino perecer, porque no se halla moneda de plata con qué comprarlo» ${ }^{12}$. De manera inexorable, los ibicencos cada vez entregaron más sal por sus importaciones de frumentos. En 1646, el gobernador Leandro Lloris explicaba que la cuartera de trigo, que antes se conseguía por un modín de sal, entonces costaba un modín y un tercio, y llegó a solicitar el envío de 7.000 fanegas de trigo desde Orán ${ }^{13}$. Incluso a fines de siglo, el último gobernador de los Austrias, el catalán Domènec de la Canal, aseguraba que en Ibiza se habían llegado a entregar dos modines de sal por una cuartera de trigo,

siendo assí que cada modín valía quatro reales de a ocho, esto era bender la necesidad, y no que una quartera de trigo ayga valido ocho reales de a ocho; y algunos de los que bendían la quartera de trigo a los referidos dos modines de sal, éstos la bolvían a tomar de

9. Archivo de la Corona de Aragón (ACA), Consejo de Aragón (CA), leg. 1035, gobernador Castellví al rey, 20/I/1634.

10. ACA, CA, leg. 1043, gobernador de Ibiza al rey, 4/III/1654. ACA, CA, leg. 1045, consulta del CA, 20/ II/1654.

11. ACA, CA, leg. 1036, consulta del CA, 9/VIII/1636.

12. ACA, CA, leg. 1036, gobernador de Ibiza, B. Salelles, al virrey de Mallorca, 3/XII/1641.

13. ACA, CA, leg. 1037, consultas del CA, 11/V/1646 y 9-23/VI/1646. 
la universidad [de Ibiza] a diez libras la polisa, que entonces valían 5 rs. de plata, y volvían a bender a los naturales el dicho trigo a dos pesos, o dos y medio por quartera [...].

Es decir, un negocio redondo ${ }^{14}$.

Las noticias sobre años de malas cosechas y la consiguiente carestía son continuas. En 1625, explicaba el gobernador Joan de Castellví «que al entrar en ella [la Real Fuerza] le salieron los muchachos a recibir pidiendo a gritos les diesse pan [...]»; ante su asombro, una vez indagado el asunto, se enteró de que no había reservas de trigo para un mes (quedaban sesenta cuarteras de trigo y ciento cincuenta de cebada en toda la isla), de manera que se solicitó al virrey de Valencia, como se había hecho otras veces, el envío de quinientos cahíces de trigo a cuenta del dinero que se iba a emplear en la compra del mismo para la guarnición de Ibiza en Orán ${ }^{15}$.

En enero de 1629, el Consejo de Aragón se hacía eco de una carta del gobernador Castellví, en la que éste explicaba cómo la necesidad había impelido a muchos naturales a sustentarse «de yerbas con aceite», habiendo decidido los jurados enviar un representante suyo a Italia y otro a las costas de Valencia y Cataluña a buscar grano. En otra del gobernador de finales de abril de 1629, éste explicaba que en enero y febrero de aquel año no hubo prácticamente pan que repartir en la isla, «[...] que ha sido cosa que de memoria de hombres no se acuerdan haber sucedido otro tanto» ${ }^{16}$.

A fines de 1646, Martín Adanzo, síndico de la isla y procurador de la guarnición de la misma, informaba al rey en un memorial sobre como habían llegado a la isla 4.000 fanegas de trigo prometidas por el monarca, y una parte del grano se

repartió para sembrar algunas tierras que había labradas, previniendo con este medio la necesidad del siguiente año y que no les quedó trigo más de para hasta mediado diciembre, y que por esta causa están los naturales de la isla como sitiados, partiendo el pan por onzas $\mathrm{y}$ comiendo hierbas por los campos, de que se han originado ya graves enfermedades $[\ldots]^{17}$.

Pero las cosas no hubieron de enmendarse lo suficiente, pues en cartas posteriores del gobernador Leandro Lloris, éste aseguraba que en los meses de abril y mayo de 1647 no se había podido comprar un pan en la isla, habiendo muerto de hambre «muchas personas que se han hallado con las bocas llenas de yerba, que para el pan que ahora se come sacó la plata labrada y el oro que tenían los particulares y también seis esclavos, que todo junto fue a venderse a Mallorca» ${ }^{18}$.

14. ACA, CA, leg. 1280, consulta del CA, 12/I/1699. Los comentarios de De la Canal en ACA, CA, leg. 1041; asesor de gobernador de Ibiza, Dr. Ignacio Benetas, al conde de Frigiliana, 18/VI/1699 y ACA, CA, leg. 1270, asesor de Ibiza, Ignacio Benetas, al protonotario del CA, Alicante, 28/VII/1699.

15. ACA, CA, leg. 1036, consultas del CA, 25/X/1624 y 31/XII/1624.

16. ACA, CA, leg. 1036, consulta del CA, 15/II/1629; gobernador al rey, 26/IV/1629.

17. ACA, CA, leg. 1037, consultas del CA, 23/I/1647 y 19/II/1647.

18. ACA, CA, leg. 1047, jurados de Ibiza al rey, 11/VI/1647. ACA, CA, leg. 1031, gobernador de Ibiza al rey, 11/VI/1647. En 1671 había noventa y seis esclavos trabajando los campos en Ibiza, de los que veinte murieron al año siguiente, ¿de hambre? ACA, CA, leg. 1044, gobernador F. Truiols a Mariana de Austria, 26/III/1673. 
En 1653, en el Consejo de Aragón se trató un memorial del jesuita padre Messeguer, quien aseguraba que en Ibiza se comenzó aquel año repartiendo siete onzas de grano por persona y día, y se acabó dándoles cuatro onzas diarias para poder estirar al máximo la reducida cantidad de grano que quedaba en existencia ${ }^{19}$.

En 1661, un acongojado gobernador Rodrigo de Borja escribía al rey cómo

la falta de agua tiene tan agostado el campo que aunque llueva no se cogerá el trigo que se ha sembrado. Y que la Universidad sólo se halla con cien cahíces para su abasto, sin un real de plata para comprarle de a fuera, ni otro medio que el de la sal que están poco seguro[s], que si llueve el mes de julio faltará ${ }^{20}$.

Y a inicios de la década de 1680, el gobernador de Ibiza, Francesc Truiols, quien había desempeñado dicho cargo entre 1670 y 1677, todavía se lamentaba de lo poco que habían cambiado las cosas en la mayor de las Pitiusas:

El terreno de la isla es muy estéril de agua, manantiales y sugeta a lograr pocas del cielo por la corta circunbalaçion que tiene, los naturales nada aplicados al beneficio de la labranza, assí por lo sucessivo de malas cosechas de tiempo immemorial, como por que siempre han tenido por su único socorro el de la sal, [h] asta que se ha reducido a ser su ruyna, con que se ven acompañados de una eterna necessidad $[\ldots]^{21}$.

Más conocida es la «hambruna» que asoló Ibiza entre 1687 y $1689^{22}$.

A lo largo del Seiscientos, pues, fue obvio que las necesidades frumentarias de la isla obligaron a todas las partes, monarca, Consejos, gobernadores, universidad de Ibiza, a procurar entenderse para lograr un objetivo común: dar de comer a los ibicencos, incluyendo en dicha categoría a aquellos que servían al rey en el presidio de Ibiza. No en vano, muy a menudo el dinero destinado a la paga de aquellos hombres se desvió para la compra de grano (en Orán, Mallorca, Valencia, Cataluña, Murcia o Cerdeña) con destino a la isla, con el compromiso de que, posteriormente, los jurados de la isla entregasen el dinero de sus pagas a los hombres de la guarnición, que llegarían a aceptar, incluso, no cobrar en plata, sino en moneda de vellón isleño. Porque, ¿qué otra cosa se podía hacer si la perspectiva, por un lado, era permanecer por varios años en la isla, y, por otra, la falta de regularidad de las pagas del rey? Con las consignaciones monetarias para las tropas, pues, se salvó algún que otro expediente (en 1597,

19. ACA, CA, leg. 1038, consultas del CA, 3/IX/1653, 9/X/1653, 10-22-26/XI/1653.

20. ACA, CA, leg. 1038, gobernador de Ibiza al rey, 19/IV/1661 y 27/V/1661.

21. ACA, CA, leg. 1280, «Papel de don Francisco Truyols que formó sobre la sal de Yviza», s. f., pero de inicios de la década de 1680.

22. SÁEnZ-Rico Urbina, A., «La penuria de trigo en Ibiza durante los años 1685-1688», en Pedralbes, 1 (1981), pp. 178-179 y 185. También hubo cosechas deficientes en la Mallorca de los siglos XVI y XVII: fueron terribles los años 1501-1502, 1505, 1507, 1556, 1566, 1591-1592, 1605-1607, 1613, 1627-1632, 1661, 1682 y 1689-1691. JUAN VidAL, J. «La evolución de la producción agrícola en Mallorca durante la Edad Moderna. Fuentes y problemas de su estudio». Moneda y Crédito, 145 (1978), pp. 67-103, esp. pp. 86-89. 
$1605,1623,1645,1653,1672$ o 1677 , entre otros muchos casos) $)^{23}$, comprando grano fuera de la isla, pero, sin duda, sólo el negocio de la sal podía permitir salir a flote a los habitantes de la Ibiza, y una climatología ${ }^{24}$ adversa la que podía hundir cualquier expectativa de futuro.

En todo caso, la experiencia ibicenca, en cuanto a la producción de cereales, parece muy distinta a la mallorquina: según datos de Josep Juan Vidal, en la mayor de las Baleares se produjeron incrementos productivos entre 1545 y 1570, frenándose luego hasta 1589, y experimentando después un nuevo auge hasta finales de siglo. Ya en el Seiscientos, se debería hablar de crisis cerealícola en Mallorca hasta 1635, con un ligero repunte productivo entre 1635 y 1645, estancándose de nuevo hasta 1660. Seguidamente, se viviría un nuevo auge productivo, especialmente marcado desde mediados de la década de 1680 y hasta el final de la guerra de Sucesión. En el siglo XVII, de noventa y ocho anualidades con datos suficientes, las cosechas fueron suficientes para alimentar a la población mallorquina en cincuenta y seis anualidades, si bien la mayor parte de los años «difíciles» se concentraron en la primera mitad de la centuria, mientras que en Ibiza, y según los datos que hemos hecho constar antes, las deficiencias fueron continuas ${ }^{25}$. También es interesante constatar cómo en el caso mallorquín la materia objeto de trueque a cambio del cereal del que se carecía no era la sal, sino el aceite, una de las escasas producciones de las que era excendentaria la isla en un momento dado (aunque siempre de forma demasiado irregular como para constituirse en una solución factible y definitiva para equilibrar el déficit productivo frumentario $)^{26}$.

\section{LA PRODUCCIÓN DE SAL Y EL DETERIORO DE LAS INSTALACIONES}

Dos grandes problemáticas afectaban a la producción de sal ibicenca: la falta de cuidados de las instalaciones -una cuestión entrelazada con las políticas salariales con respecto a la extracción de la sal- y la climatología adversa. Cuando se combinaban, la alarma cundía y llegamos a momentos de gran tensión entre administraciones, pues

23. ACA, CA, leg. 1036, consulta del CA, 9/VII/1598 y A. Çanoguera, gobernador de Ibiza, a Felipe III, 3/ XII/1598 y 22/X/1605; consultas del CA, 29/VIII/1623 y 17/XII/1623; consultas del CA, 29/V/1627 y 13/XI/1627. ACA, CA, leg. 1037, consultas del CA, 5-9/IX/1645. ACA, CA, leg. 1045, gobernador F. Miguel al rey, 30/XI/1656. ACA, CA, leg. 1038, jurados de Ibiza al rey, 26-28/VI/1661. Dietaris de la Generalitat de Catalunya, vol. VII, Anys 1656 a 1674. Barcelona: Generalitat de Catalunya, 2002, pp. 458-459 y 466. ACA, CA, leg. 1037, gobernador de Ibiza al CA, 16/VII/1677.

24. Sobre Climatología histórica son interesantes las aportaciones de BARRIENDOS, M., «La climatología histórica en el contexto universitario español», en Pedralbes, 26 (2006), pp. 41-64. Y también su trabajo «Climatologia històrica. Reflexions sobre les seves dificultats i potencialitats a Espanya», en Afers, vol. 26, n. ${ }^{\circ} 69$ (2011), pp. 295-310.

25. JUAN VidAL, J. «La evolución de la producción agrícola en Mallorca durante la Edad Moderna. Fuentes y problemas de su estudio». Moneda y Crédito, 145 (1978), pp. 67-103, esp. pp. 77-78, 84-89.

26. JuAn VidaL, J. «Las crisis agrarias y la sociedad en la época moderna», en Mayurqa, 16 (1978), pp. 87-113, esp. pp. 109-110. 
se veía en riesgo la supervivencia económica de un jalón muy importante en las rutas hispánicas del Mediterráneo.

Ya en 1598, con varios años de malas cosechas frumentarias y dos de falta de producción suficiente de sal, las alarmas sonaron en el seno del Consejo de Aragón. La postura isleña era muy clara: se pedía una aportación de dinero de los tres conseñores (el monarca, el arzobispo de Tarragona y el arcediano de San Fructuoso de Tarragona) para terminar de arreglar las salinas y también la torre de defensa del cargador de la sal, donde se cobijaban los trabajadores en caso de peligro, todo lo cual necesitaba de unos mil ducados. Una vez interrogado el gobernador Alonso de Çanoguera al respecto, éste respondió señalando que

[...] el estaño principal de la sal de Ibiza está dividido en tres partes con dos calzadas ${ }^{27}$ de cal y canto; la primera se llama el Estaño Mayor, la segunda la Punta, y la tercera el Codolar, en la cual no se cuaja la sal porque cuando corren vientos lebeches contra el agua de la mar es fría por allí, y que para defender que esta agua no pase a los otros estaños en tiempo que hace daño se hicieron las dichas calzadas con sus puertas para meter y sacar el agua a sus tiempos, que por no haber ido conservando estas calzadas se perdió la una casi toda, y los años pasados la universidad reedificó la mitad de ella a su costa sin haber podido hacer más por su poca posibilidad [...] Que la segunda calzada que divide el estaño de la Punta está desmoronada y caída de tal manera que solamente ha quedado los cimientos y así el agua viene a ser común del un estaño al otro, según los vientos que corren, que para remedio de esto conviene que las dos calzadas que costarán dos mil ducados poco más o menos se acaben perfectamente.

Según Çanoguera, debido a las pérdidas causadas por el mal estado de las calzadas, el rey podía perder dos mil ducados en derechos y otros tantos el arzobispo de Tarragona y el arcediano de San Fructuoso, sin contar el daño recibido por la Universidad, que se mantenía gracias a las salinas. En su opinión, a poco que el rey se decidiera por invertir setecientos ducados, además de lo que pusiesen los otros dos conseñores $^{28}$, el tema podría resolverse en un año. Sobre la torre del cargador de la sal, Çanoguera apuntó lo siguiente:

[...] ha mucho que se començó [en 1582] y della está hecha la mayor parte, aunque no se ha puesto en defensa, y que del daño que de no acaballa podría resultar sería tan grande que en cinquenta años no le podría reparar la isla, porque sucediendo que un día de cargador abierto (que son muchos entre año) hiciesen los turcos una emboscada (como otras veces lo han intentado) se podrían llevar quinientas personas, los más de ellos muchachos,

27. En su descripción de 1803, Jaume Cirer habla de la existencia de dos calzadas, llamadas d'En Macià y del Codolar, también con problemas de mantenimiento. Cirer Pons, J., Tratado de las reales salinas de Yviza y Formentera: que comprende el manejo antiguo quando se governaban por la Universidad de dicha ysla y el posterior desde que se incorporaron a la Corona, con varias instrucciones para sus fábricas: obra de Jaume Cirer Pons c. 1803, introducción y transcripción de A. Ferrer Abárzuza. Ibiza: Mediterrània, 2000, p. 50.

28. El arzobispo de Tarragona se negó a aportar cantidad alguna, y Felipe III le escribió solicitándole la documentación donde constase que no estaba obligado a contribuir a ningún gasto. Al respecto, EsCANDELL, B., Ibiza y Formentera en la Corona de Aragón. Tomo III/1, p. 82. 
y matar trescientos pares de mulas, lo qual les será muy dificultoso estando la torre acabada $[\ldots]$.

Çanoguera preveía que si la torre pudiese contar con dos piezas de artillería sería mucho más conveniente como abrigo de los trabajadores y sus animales, pero las dificultades económicas de la Universidad para cubrir el gasto de la torre, que tenía un presupuesto de mil ducados, le llevaron a solicitar el dinero al monarca y el resto de los conseñores de la isla ${ }^{29}$. Pocas obras se hicieron en la torre del Cargador, y en cuanto a su artillería, en 1659 contaba con una sola pieza de tres libras de calibre, que para 1692 había sido sustituida por otra de hierro de ocho libras de calibre ${ }^{30}$.

Por su parte, en 1646 la crisis alcanzó la isla «por haverse anegado los estanques de la sal cuia cosecha era el remedio con que se abastecía todo género de bíveres y bastimentos, y en especial de trigo [...]», de modo que el gobernador, Leandro Lloris, se lanzó inmediatamente a una mejora de los estanques de la sal (renovó algunas calzadas y levantó una pared para desviar el curso de un torrente de agua que irrumpía en las salinas) de la que no dudó en informar orgulloso de haber obligado a los ibicencos a afrontar aquellos gastos «en el tiempo de su mayor [h]ambre y más pobressa [...]» ${ }^{31}$.

Para 1662, cuando el síndico de Ibiza, el pavorde Mariano Castany, informaba al rey sobre el negocio de la sal en su isla, aquél ya podía argumentar que la producción estaba cayendo en picado. En su opinión, si la sal ibicenca no se vendía por un precio ajustado al alza los estanques se irían perdiendo por falta de cuidados, y la consecuencia ya se veía en aquellos años: en los últimos diez apenas si se habían extraído 5.000 modines anuales ${ }^{32}$. Lo cierto es que desde inicios de siglo algunas voces señalaban que los estanques ibicencos podían producir hasta 15.000 modines anuales, pero que su producción efectiva era de $8.000 \mathrm{o}$, con suerte, 10.000 modines (y sin problemas climáticos). En 1663, el mercader ibicenco de origen monegasco, Juan B. Botino, en un informe que le había solicitado el vicecanciller del Consejo de Aragón, C. Crespí de Valldaura, afirmaba que las salinas de la isla, de invertirse en sus instalaciones, podían producir hasta 50.000 modines de sal anuales (una exageración), pero no lo eran sus informaciones sobre lo que estaba pasando: Botino comenzó por señalar que Venecia, Génova y Vilafranca de Niza compraban mucha sal en Trípoli con el pretexto de que en Ibiza o no había suficiente o bien la sal ibicenca había perdido la calidad de antaño (al menos en los últimos ocho años) a causa del lodo que ensuciaba los estanques de la misma, y en especial en los tres últimos años, cuando se habían producido muchas lluvias. Una solución, según Botino, era que el rey se mostrase muy firme en la persecución de aquéllos que introdujesen sal de Trípoli en Milán y mercadeasen con ella,

29. Citas en ACA, CA, leg. 1035, consulta del CA, 13/VIII/1598. ACA, CA, leg. 1036, consultas del CA, 9/ VIII/1598 y 5/I/1599; gobernador Çanoguera al rey, 3/XII/1598.

30. ACA, CA, leg. 1037, consulta del CA, 1/VII/1659. ACA, CA, leg. 1038, el gobernador de Ibiza, don Lupercio Castellón, al presidente del CA, 20/V/1692.

31. ACA, CA, leg. 1037, consultas del CA, 23/I/1647 y 19/II/1647. ACA, CA, leg. 1031, gobernador L. Lloris al rey, 11/VI/1647.

32. BN, VE, 25-63, «Señor, el doctor y paborde Mariano Castany, syndico de la isla de Ibiza [...]», 1662. 
evitando comprarla en la isla, donde la sal era abundante y de gran calidad aquel año; por otro lado, recordaba Botino que la Cámara de Milán tenía la obligación de tomar cada año 148.772 staia de sal roja ibicenca ${ }^{33}$. Pero Botino también instó al rey a que enviase órdenes a su gobernador en la isla para que éste, sin dejar de lado la posibilidad de aplicar graves penas, obligase a los jurados a que limpiasen de lodo los estanques de las salinas para garantizar una buena cosecha de sal, y a que mantuviesen su calidad, pues a causa de dicha contingencia, en aquellos momentos los genoveses no la querían y en Venecia sólo la pagaban a 16 reales el modín (cuando Felipe IV había decretado su venta a 32 reales por modín en 1662$)^{34}$.

De alguna cosa sirvió aquel aviso, pues con fecha del 21 de enero de 1665 Felipe IV emitió una orden para limpiar los estanques de la sal, orden que se hubo de repetir el 9 de agosto de 1666 ante la falta de acción por parte de los jurados de Ibiza. Éstos, en carta del 28 de noviembre de 1666, alegaban que

los dichos estanques consisten en dos lagos de agua que quando viene el verano con la esterilidad del tiempo y sus calores se quaja y convierte en sal; no es posible que sin haver primero sacado la sal, estando dichos estanques enjutos, se puedan limpiar, y este año sacándola fue Dios servido dar una tan grande lluvia que lo anegó todo sin ser posible poder acabar de sacar la sal, ni menos limpiarla [...].

Pero tras la excusa, que servía para el verano de 1666, pero no para el de 1665 , si bien en este último año había sido competencia de otros jurados, aseguraron que harían todo lo posible por cumplir la orden real.

Dos días más tarde, el 30 de noviembre, escribía el gobernador, Jerónimo García, explicando que había sido ciertamente imposible por las lluvias no sólo limpiar los estanques, sino conseguir una buena cosecha de sal -en septiembre había señalado cómo una posible cosecha de 12.000 modines apenas si alcanzaría los 4.000 a causa de las precipitaciones sobrevenidas-, si bien se había salvado algo de sal blanca aquel año y con la que aún quedaba del año anterior intentaría colocarla en el mercado, pero el problema persistente era "conseguir que vengan naves a cargar de sal, pues por a[h] ora están desterradas, sin que [a]parezca una [...]». Por ello el gobernador recordó una vez más la necesidad de que se obligase a los arrendadores de la sal de Milán para que la adquiriesen en Ibiza (y no en Trípoli) ${ }^{35}$.

Y en septiembre de 1667, en nueva carta del gobernador J. García, éste aseveraba que se había sacado una buena cantidad de sal y se había iniciado la limpieza de cieno de los estanques, hasta que se hubo de parar este trabajo por haber caído nuevas tormentas; no obstante, parecía que las obras realizadas resultarían suficientes como para

33. Así era, al menos, desde 1644. Archivo Histórico Nacional (AHN), Estado, leg. 1953, «Capitoli della ferma generale del sale dello Stato di Milano per gl'anni 1644, 1645, 1646, 1647, 1648, 1649 deliberata à Ludovico Porraneo».

34. ACA, CA, leg. 1036, Juan B. Botino al vicecanciller del CA, Crespí de Valldaura, 10/XI/1663.

35. ACA, CA, leg. 1035, J. García, gobernador de Ibiza, a Mariana de Austria, 17/VII/1666; jurados de Ibiza a Mariana de Austria, 28/XI/1666; gobernador de Ibiza a Mariana de Austria, 30/XI/1666. ACA, CA, leg. 1036, J. García a Mariana de Austria, 25/IX/1666. 
conseguir una buena cosecha, o al menos así lo esperaba el gobernador: «La sal blanca de este año es muy excelente y se haze todo el esfuerzo posible para sacar grande cantidad $[\ldots] .{ }^{36}$

Todo indica que, a partir de aquellos años, los gobernadores de Ibiza mostraron una mayor sensibilidad hacia la cuestión de la limpieza de los lodos en los estanques de la sal. En un informe anónimo de hacia 1670 se leía que las salinas probablemente sólo producían a la mitad de su capacidad -se obtenían por entonces en un buen año hasta 10.000 modines de sal roja ${ }^{37}$ y 5.000 de sal blanca- dados los lodos que las avenidas de agua introducían cada invierno; por otro lado, los naturales no se aplicaban a su limpieza, que era la solución lógica para el problema, a causa de la «mala satisfacción que se les da de su trabajo» ${ }^{38}$.

El caso es que en Ibiza, los trabajadores cobraban cuarenta sueldos ibicencos (dos libras) de la universidad por cada modín de sal extraído, pero entre 1622 y 1639 el salario -nunca mejor empleado este término- se redujo a treinta y cinco sueldos (los cincos sueldos ahorrados por la Universidad se destinaron a que ésta pagase a sus acreedores). Un problema grave en el último tercio del siglo XVII era la depreciación de la moneda ibicenca: las dos libras, que habían valido catorce reales de plata castellanos a inicios del Seiscientos, apenas si alcanzaban dos reales de plata hacia 1680. Incluso en 1699, el gobernador De la Canal trató que los trabajadores cobrasen cuatro reales de plata por modín extraído ${ }^{39}$. Otro gobernador, Félix Vegués, sí fue sensible con aquella problemática: en 1683 explicó que los habitantes de la parte foránea de Ibiza estaban cansados de la forma cómo se explotaban las salinas y lo mal que se les pagaba por su trabajo, «pues se les está debiendo de muchos años cantidades atrasadas», de manera que,

con la fuerza de la razón que tienen, pasan a decir públicamente que si V. Magd. no pone quien administre estas salinas para ser satisfechos, están resueltos a dejarla perder [la sal] dentro los estanques, y más este año que dan muestras de mayor cosecha que los pasados, pues se conoce que si las inclemencias de las aguas se dilatan hasta últimos de julio a lo más largo estará la sal en estado de sacarse.

Y no se equivocaba Vegués, ya que en su informe de agosto de aquel año pudo señalar que se habían obtenido 7.000 modines de sal roja y 3.000 de sal blanca y

36. ACA, CA, leg. 1036, J. García a Mariana de Austria, 20/VIII/1667 y 25/IX/1667.

37. Era muy apreciada en Milán la llamada «sal roja» de Ibiza que, por su precio y calidad, no tenía rival entre las que «[...] suelen introducir los impresarios desde Venecia y otras partes, afectando con remedios fraudulentos la semejanza del color de la de Ibiza». Archivo General de Simancas (AGS), Secretarías provinciales (SSP), leg. 2074, Felipe IV al gobernador de Milán, 3/VI/1664. En una carta del magistrado ordinario de Milán al duque de Sermoneta, gobernador del Estado, aquél aseguraba que era conocido cómo se compraba sal en Berbería «e con terra colorata la facessero dell'estesso colore» que la famosa sal roja ibicenca. AGS, SSP, leg. 2074/279, consulta del magistrado ordinario, 10/VI/1661.

38. ACA, CA, leg. 1036, informe anónimo titulado «Sal de Ibiza», c. 1670.

39. ACA, CA, leg. 1041, asesor de gobernador de Ibiza, Ignacio Benetas, al conde de Frigiliana, 18/VI/1699. ACA, CA, leg. 1270, asesor de Ibiza, Dr. Ignacio Benetas, al protonotario del CA, Alicante, 28/VII/1699. 
había empezado ya a enviar embarcaciones con la misma ${ }^{40}$. Como observamos, 10.000 modines se consideraba por entonces una excelente cosecha de sal. Quizá animado por dicho resultado (y sin olvidar que la universidad de Ibiza le debía al Real Patrimonio en la isla 45.000 libras y deseaba cobrarlas), Carlos II volvió a tratar sobre la posibilidad de mejorar las salinas pitiusas en base al desvío de las aguas de lluvia que desde las montañas bajaban hasta los estanques y los llenaban de impurezas, pero las obras se calibraban en 480.000 reales de plata y se dieron por imposibles de pagar en aquellas circunstancias $^{41}$. De todas formas, el sucesor de Vegués, el oscense Juan Bayarte, asumió su cargo con la orden de mejorar la producción salinera de la isla.

Elegido en mayo de 1684 para el cargo de gobernador de Ibiza, en enero de 1685 ya tuvo don Juan Bayarte oportunidad de realizar su primera visita y de enviar al presidente del Consejo de Aragón sus primeras impresiones de las salinas, fuente inapreciable para conocer el estado de las mismas. Por ejemplo, el llamado estanque de la sal roja

[...] se va continuamente cegando con la tierra que le conducen a las colinas vecinas las aguas que llueve, de que se sigue que ellas disponen mal las salobres para cuajarse, y la tierra que se incorpora con la del suelo es impedimento para lo mismo. Demás de que todo lo que ocupa y levanta el plano natural falta de agua que se cuajaría [...] este daño crece de modo [que] con el tiempo se va aumentando mucho; su remedio consiste en fabricar una presa o pared que desvíe el agua llovediza.

En un segundo informe de mayo de 1685, Bayarte aseguraba que pocos días antes había tenido una reunión con personas prácticas de la isla sobre la producción de la $\mathrm{sal}^{42} \mathrm{y}$ todos le habían manifestado que muchos estanques -había algunos que no se aprovechaban directamente, proponiendo Bayarte como primera medida que todos y cada uno produjeran- estaban con problemas de lodos a causa de las calzadas que se habían construido, cuyos escombros caían sobre los mismos si no se retiraban pronto (materia superable, decía Bayarte, aunque con un aumento del precio de las obras en una cuarta o una quinta parte). Otra dificultad era acertar con la cantidad de agua que debía haber en los estanques al iniciar el proceso de evaporación, sacándola o añadiéndola,

40. Todo parece indicar que la sal se vendió, pues en una Real Orden de fines de enero de 1684 el rey se hacía eco que desde agosto de 1683 se habían sacado 10.000 modines de sal de las salinas ibicencas y las iban vendido, recordando que se debían cobrar los derechos de los que se sustentaba el Real Patrimonio en la isla. ACA, CA, leg. 1041, Real Orden, 29/I/1684.

41. ACA, CA, leg. 1280, consulta del CA, 20/XII/1683.

42. En 1683 se extrajeron 9.600 modines de sal; en 1684 fueron 7.200 modines y en 1685 se sacarían unos 5.600; de hecho Bayarte obtuvo una relación de la producción de los últimos diez años y el resultado fue una media de 4.100 modines al año. ACA, CA, leg. 1280, don Juan Bayarte al rey, 2/V/1685. La labor del gobernador Juan Bayarte, y la de su hijo Pedro Bayarte, acerca de la sal ibicenca se trata en EsPINO LóPEZ, A., «La sal de Ibiza y Carlos II. Control político y control económico de una fuente de riqueza en la antesala del cambio dinástico, 1683-1691», en Obradoiro de Historia Moderna, 18 (2009), pp. 181-209. 
y como esto se hace mediante dos ruedas a fuerça de brazos con poca operación y mucha costa quando los vientos no son favorables para el mismo efecto, conviene introducir cierta máquina de la que he hecho hacer el modelo, fácil y de poco gasto, con la qual se sacará, por lo menos, quatro veces más agua, y no será el coste la quarta parte de que agora se causa ${ }^{43}$.

También el muelle se hallaba arruinado por no haberse invertido nada a tiempo, pensando que lo mejor era aplicar recursos del Real Patrimonio para acabar cuanto antes con la mala situación del mismo ${ }^{44}$.

Un par de años más tarde, Juan Bayarte continuó insistiendo en las terribles condiciones de trabajo en las salinas de Ibiza $^{45}$, con una -increíble- «[...] total falta de agua potable para los laborantes y sus acémilas en un lugar y tiempo de calores y soles insufribles [...]», y las dificultades de acarreo y almacenamiento de la sal por «la mala disposición de algunos pasos en el camino desde el propio estanque al cargador de poniente, por el peligro de despeñarse a la mar las acémilas, y por lo menos derramándose en el porteo mucha sal». Bayarte se puso a la labor construyendo un aljibe para almacenar agua para trabajadores y bestias de acarreo, así como en la mejora los caminos. También hacía progresos en el muelle de carga de poniente, pues apenas se había corrido doce pasos hacia levante el canal que llevaba agua al mismo y retirada una peña que difícultaba el acceso, las barcas salineras ya podían volver a cargar sal directamente del muelle, ahorrándose un tercio del tiempo. Pero aún faltaban algunas otras mejoras por introducir ${ }^{46}$. De todas formas, las innovaciones pensadas por el gobernador Bayarte apenas si se llevaron a cabo pues, entre otras razones, las condiciones climatológicas adversas fueron realmente muy recurrentes a fines del Seiscientos en Ibiza y afectaron sobremanera la producción salinera.

\section{UNA CLIMATOLOGÍA HOSTIL}

Como decíamos, una climatología hostil también podía ser letal a la hora de impedir una cosecha de sal abundante. Es lo ocurrido en 1605, cuando, como informaba el gobernador Çanoguera, se anegaron

los tres estaños mayores sin que de ellos se halla aprovechado de un grano, cosa que no es memoria de gentes que de tal se acuerden [...] y las aguas del cielo fueron tantas en los meses pasados de agosto y septiembre que no se pudieron sacar de ellos más de ochocientos modines y así ha quedado esta pobre isla $[\ldots]^{47}$.

43. ACA, CA, leg. 1280, Juan Bayarte al rey, 19/V/1685.

44. ACA, CA, leg. 1036, Juan Bayarte al presidente del CA, 9/I/1685.

45. Sobre las condiciones de trabajo en las minas de sal el reciente trabajo de HocQuET, Jean-Claude, «Travailler aux mines de sel: réquisitions, corvées, travail forcé et esclavage», en Revue Historique, n. $^{\circ}$ 640, 2006, pp. 779-812.

46. ACA, CA, leg. 1280, Juan Bayarte al rey, 23/X/1686.

47. ACA, CA, leg. 1036, gobernador Çanoguera a Felipe III, 22/X/1605 y respuesta del CA. 
En 1631 hubo suerte, pues con apenas 3.000 modines de sal recogidos al interrumpirse la cosecha por unas fuertes tormentas en agosto,

[...] después con la falta que ha habido de aguas y los excessivos calores que han hecho ha vuelto a cuajar la sal, visto lo cual los jurados resolvieron, para animar a los naturales a sacarla, hazer pregón de que la dejarían sacar francamente, sin pagar gastos, y animados con esto han acudido muchos a sacarla $[\ldots]$,

y el resultado fue que, por entonces, se creía que eran ya 8.000 los modines de sal extraídos, explicaba en noviembre de dicho año el gobernador Castellvít8.

Dos años más tarde, y tras una terrible sequía ${ }^{49}$, el gobernador Castellví esperaba que, por lo menos, las tormentas respetaran la cosecha de la sal en agosto e inicios de septiembre, única fórmula para llenar los graneros y despensas de la isla, dado que «no han quedado aceitunas en los olivos, y de trigo y cebada hay muy corta cosecha, pues hayan harto que se coja para sembrar $[\ldots]\rangle^{50}$.

En 1646 también se anegaron los estanques de la sal y se perdió la cosecha de la misma, el único «remedio con que se abastecía todo género de bíveres y bastimentos, y en especial de trigo [...]», explicó en la corte en enero de 1647 Martín Adanzo y Beortegui, síndico de Ibiza y procurador de la gente de guerra de su presidio ${ }^{51}$.

Una década más tarde, de nuevo la mala fortuna climatológica pareció cebarse con las salinas, pero al final el expediente se salvó. Mientras en julio de 1655, y tras medio año de sequía, el gobernador F. Miguel podía informar de que

Los estaños de la sal caminan prósperamente, y de la blanca que se gasta en Cataluña, Mallorca y Menorca se [h] an sacado ya pasados de tres mil modines y se va continuando el trabajo; la Rossa que se consume en Italia [...] se empezará a sacar al otro día de San Roque librándonos de aguas y espero que [...] de una y otra se juntarán pasados de veinte mil modines $[\ldots]^{52}$.

En agosto escribía F. Miguel informando que la noche del 14 al 15 de agosto llovió tal cantidad de agua que, acompañado de los jurados, todos ellos fueron a visitar las salinas, que encontraron con cuatro dedos de agua, y ante el consejo de los mayores, se decidió que después del día de san Bartolomé se empezaría el trabajo de extraerla, prometiéndose pagar en plata a los salineros; gracias a dicha medida acudió mucha gente a trabajar y en apenas quince días de labor se obtuvieron 9.000 modines de sal roja y 4.000 de sal blanca, todo ello con el riesgo de que en cualquier momento llegasen nue-

48. ACA, CA, leg. 1034, gobernador Castellví al rey, 7/XI/1631 y jurados de Ibiza al rey, 10/XI/1631.

49. El trabajo al respecto más destacado para las Baleares es el de Grimalt Gelabert, M. y LAita RUIZ DE AsúA, M., «Periodización de las sequías históricas en Mallorca (siglos XIV-XIX), en Cambios y variaciones climáticas en España. Santa María de la Rábida: Asociación de Geógrafos Españoles, 1994, pp. 129-146.

50. ACA, CA, leg. 1034, gobernador de Ibiza al rey, 20/VII/1634.

51. Comentarios sobre el informe de Adanzo en ACA, CA, leg. 1037, consultas del CA, 23/I/1647 y 19/ II/1647.

52. ACA, CA, leg. 1035, gobernador F. Miguel al rey, 23/VII/1655. 
vas lluvias, de modo que al gobernador Miguel le parecía un milagro lo mucho conseguido y esperaba que todo parase en beneficio de la Universidad y el Real Patrimonio ${ }^{53}$.

En 1669 la Corona estaba muy interesada en obtener algunos ingresos por cuenta de la sal de Ibiza, de modo que Mariana de Austria escribió con regularidad al gobernador de su hijo en la isla, J. San Juan Sureda, solicitándole información sobre la cosecha de la misma. Es una correspondencia interesante, pues permite conocer mejor algunos aspectos de la meteorología de la época (y sobre el estado de las salinas): en carta de junio de 1669, San Juan Sureda explicaba cómo «los estaños corren muy faborables, si bien ayer y el día antes estuvo el cielo algo turbio y dio principio a un poco de agua, que no fue nada, [h] oy se muestra apacible, con que confío en la misericordia Divina, continuando esta bonanza se a de lograr una gran cosecha [...]». Y en agosto insistía en que aquel año la cosecha de sal era muy importante por no haber sido buena la de grano, por ello habían estado todos con el corazón en un puño cuando «una tarde cayó en la parte de los estaños tanta agua, que fue forzoso apellidar al Autor desta causa misericordia [...]»; haciéndose acompañar por el cabildo catedralicio y con toque de campanas incluido, el gobernador solicitó la ayuda divina ${ }^{54}$ y el cese de la furia de los elementos que habían imposibilitado el trabajo de los salineros. Y, milagrosamente, algo positivo ocurrió:

al día siguiente salió el sol tan abrasante que se conoció la menguante del agua, con que los traientes empezaron de nuevo con todo annelo el trabajo y [...] se ha conseguido la extracción libre ya de riesgos de cantidad de doze mil modines de sal entre roja y blanca y de tal calidad que no se ha visto tan hermosa de muchos años a esta parte $[\ldots]^{55}$.

En 1671 el nuevo gobernador, Francesc Truiols, era optimista con respecto a la producción salinera de Ibiza, y pensaba que aún sería mejor en 1672, «siendo en el presente tan colmada la del estanque blanco que de 50 años a esta parte aseguran no haberse visto, más bien es verdad que hacía otros tantos que no se había podido sacar la sal de la parte donde se ha sacado a[h]ora» ${ }^{56}$. Y, realmente, las cosas no fueron del todo mal en 1672, según el gobernador Truiols en carta a Mariana de Austria de primeros de octubre, aunque siempre se puede pintar todo con tintes dramáticos: «La saca de sal que se ha conseguido este año de los estanques llegará a catorce mill modines, que según las muchas aguas que tuvimos en el invierno, y las enfermedades que está padeciendo a[h]ora la isla no ha sido poco», pero al no haber podido acceder al trabajo de recolección por dichos motivos hasta demasiado tarde (los trabajos se retrasaron

53. ACA, CA, leg. 1035, gobernador F. Miguel al rey, 15/IX/1655.

54. Sobre la cuestión de la llamada religiosidad instrumental, véase PERIS AlBEntosA, T., «La religiosidad instrumental comunitaria en la ribera del Júcar durante los siglos XVI-XVIII: el ejemplo de las rogativas», en Alberola, A. y Olcina J. (Eds.), Desastre natural, vida cotidiana y religiosidad popular en la España moderna y contemporánea. Alicante: Universidad de Alicante, 2009, pp. 335-389.

55. ACA, CA, leg. 1035, gobernador de Ibiza, San Juan y Sureda, a Mariana de Austria, 28/VI/1669; borrador de carta de Mariana de Austria al gobernador de Ibiza, 24/I/1669; gobernador de Ibiza, San Juan y Sureda, a Mariana de Austria, 30/VIII/1669.

56. ACA, CA, leg. 1035, gobernador Truiols a Mariana de Austria, 15/IX/1671. 
un mes y medio), dicha circunstancia sólo sirvió para que «cogiéndonos la entrada del invierno en el trabajo, [h] aya llobido ocho días ha, de manera que se [h]ayan perdido más de siete mil modines que ya estaba cabada ${ }^{57}$.

Pero los años finales del Seiscientos fueron terribles en la mayor de las Pitiusas. En 1687, el gobernador interino, Pedro Bayarte, explicaría al rey cómo el 21 de julio se comenzó a trabajar en el estanque rojo y se continuó la labor hasta el 7 de agosto, con la intención de descansar el día 8, por ser fiesta, y continuar los trabajos el día siguiente, «[...] pero fue Ntro. Sr. Servido quitarnos el buen logro que podíamos esperar por medio de una tempestad de agua que el referido día nuebe por la madrugada nos llenó assí el estanque rojo, como el de la blanca, bien que teníamos ya mucha sal roja en tierra». Aseguraba Pedro Bayarte que en el estanque rojo se encontraron con hasta dos palmos de agua, la cual había derretido la sal existente por entonces, unos mil modines, pero, sobre todo, la tromba de agua lo que había hecho era acabar con sus esperanzas de poder limpiar aquel año hasta treinta calzadas, un servicio que ya tenía ajustado con los habitantes de los cuartones y la villa de Ibiza y que en 1688 tendría que renegociar. Con todo, de momento creía que se habían obtenido 4.500 modines, aunque habría que purificar aquella sal y el monto total alcanzaría una cantidad inferior. Por su parte, cuando visitó el estanque de la sal blanca halló en él hasta un palmo y medio de agua, si bien comenzaba a dejarse ver bien formadas algunas cantidades de sal tanto «en el medio [del estanque] como en las orillas», de modo que con una cierta esperanza de lograr alguna cosecha ordenó que se midiera la cantidad de agua cada tres días, quedando seis dedos para el día 20 de agosto, pero como había lugares con tres y cuatro dedos de sal de muy buena calidad, el día 22 se decidió comenzar a sacar agua y poder recoger una buena porción de sal blanca, cosa que podrían hacer «si no lluebe en estos quince días que tendremos [...]». Su idea era achicar agua hasta el día 28 de agosto, y al día siguiente, sin descansar ni los domingos merced a «la licencia que el vicario general $[\mathrm{h}] \mathrm{a}$ concedido para ello», que se fuese a extraer toda la sal que se pudiera. Por otro lado, volvió a reconocer el estanque de la sal roja encontrado en él «un palmo de agua, y con muestras de sal nueba, las quales tienen medio dedo de grueso en el centro del estanque». Pedro Bayarte consideraba que si no llovía en todo septiembre «tendremos segunda cosecha» ${ }^{58}$.

En 1689 también un exceso de aguas anegó los estanques de la sal y los llenaron de lodos, una situación que fue aprovechada en 1691 por algunos prohombres de la isla, enfrentados políticamente a Pedro Bayarte, quienes, en agosto dijeron que la sal no se podía extraer por ser de mala calidad y los posibles clientes se sentirían insatisfechos y se perdería a la larga el prestigio de la sal de la isla. Pero Pedro Bayarte se informó en secreto con gente sencilla, pero práctica en la materia, de la isla y éstos le aseguraron que la sal era buena a todos los efectos. Así, Pedro Bayarte obligó a seguir los trabajos de extracción con toda rapidez, pero se habían perdido algunos días, de

57. ACA, CA, leg. 1036, gobernador Truiols a Mariana de Austria, 3/X/1672.

58. ACA, CA, leg. 1035, Pedro Bayarte al rey, 24/VIII/1687. 
modo que se evaluaron en 2.000 los modines que dejaron de extraer. El caso es que entre 1689 y 1691 nadie había eliminado los lodos de los estanques ibicencos y entonces llegaban aquellas consecuencias ${ }^{59}$.

Pero la desgracia continuó cebándose con Ibiza. El 24 de noviembre de 1694 una gran borrasca propició una enorme crecida del mar y la rotura de los estanques de la sal -el viento empujó el mar con tal fuerza que éste invadió por la zona del cabo Codolar las salinas-, llevándose 8.000 modines de sal roja y blanca que aún no se habían embarcado (pues sólo un navío genovés se llevó 200 modines de sal roja, hundiéndose, por cierto, a causa de la borrasca). Aseguraba el gobernador Lupercio Castellón que las gentes de Ibiza no recordaban un temporal tan dañino como aquel, con unas pérdidas tan grandes. Éstas se evaluaron en 192.000 reales (si se hubiesen vendido esos 8.000 modines), obligando el gobernador a todo el mundo, clérigos incluidos, a trabajar en las salinas para acondicionarlas, cavando zanjas para evacuar el agua, y limpiarlas de las inmundicias que había traído el mar.

Es más, recordaba Castellón que si las salinas se perdían, no sólo sería el final de la población, que carecía de otro medio de sustento, sino también de la guarnición, pues por Real Orden del 24 de marzo de 1688 el rey había decidido aplicar el derecho del nuevo impuesto de la sal de Ibiza para el sustento de la gente de guerra ante el atraso con el que llegaba el dinero para su dotación (teóricamente 120.000 reales remitidos en tres pagas). El problema, señalaba Castellón, era que desde el inicio de la guerra con Francia «no passaba el derecho del nuevo impuesto un año con otro de 400 pesos», cantidad exigua con la que se compraba un poco de trigo hasta que el asentista de grano enviaba alguna partida a la isla para las tropas ${ }^{60}$.

Tras la borrasca de 1694, que rompió parte de las calzadas, justamente por ello fue necesario comenzar a construir un

paredón [...] de quatorse palmos de $<\mathrm{h}>$ ancho, re[e]dificando otra [calzada] que había, y haziendo ésta mayor, más alta y más larga en esto, y en otro paredón que se ha hecho alrededor de dicho estanque para que no entre la tierra e inmundicias que solía traher se han gastado quarenta y siete mil libras de esta moneda de bellón $[\ldots]^{61}$.

Y para colmo de males, tampoco hubo recuperación en 1695. Lupercio Castellón escribía a Carlos II en noviembre de 1695 y le informaba de que el primero de octubre

fue servido (sic) la Divina Magd. embiarles de agua, truenos, relámpagos y viento que parecía segundo diluvio y que no solamente ha anegado los estanques de la sal que estaban para secarse, sino que ha hecho caer algunas casas, haviendo dexado semejante ruina atónitos los hombres de más crecida hedad por no haver oido decir que huviese ocurrido otro tanto en aquella ysla.

La paradoja era que, con una pérdida tan grande, ahora la Universidad no sólo debería traer bastimentos de otros lugares, sino hasta la propia sal que se consumiese

59. ACA, CA, leg. 1035, Pedro Bayarte al rey, 24/IX/1691.

60. ACA, CA, leg. 1036, consulta del CA, 11/I/1695; Lupercio Castellón al rey, 30/XI/1694 y 20/III/1695.

61. ACA, CA, leg. 1037, gobernador Domingo de la Canal a Felipe V, 18/IX/1704. 
en la isla. Ante la agónica carta de unos aterrados jurados que se encontraban en la pobreza más absoluta y reclamaban la ayuda del rey, el Consejo de Aragón reiteró que al no haber ingresos extras por el cobro de derechos sobre la sal embarcada, por tanto el asentista de dinero de la guarnición de Ibiza debería volver a contribuir con 120.000 reales anuales (y no con los 48.000 reales que enviaba desde la Real Orden de 1688 de aplicar los ingresos del rey sobre la sal de Ibiza al mantenimiento de la guarnición de la misma $)^{62}$.

En 1696, un exceso de frío había ralentizado hasta mediados de julio que la sal comenzase a «cuajar», además de que la mucha agua que había en el «estañol de la sal blanca» impidió que los ibicencos entrasen a por ella hasta el 22 de agosto, sacando unos 700 modines que, en primer lugar, sirvieron para el abastecimiento de la propia isla, «y de lo que ha quedado se han cargado dos navíos genoveses, $\mathrm{y}$ estan para cargar dos o tres $<\mathrm{h}>$ embarcaciones deste puerto, que es hasta donde podrá llegar la sal que ha quedado». En cuanto al estanque de la sal roja, decía L. Castellón que

[...] biendo que la mucha agua que tenía no acababa de consumirse, se procuraron ruedas y gente para agotarla, por ver si se sacaría alguna partida de sal, pero la misma lluvia bolvió a llenarle quando le teníamos en buen estado; estas y otras muchas diligencias se han hecho en los estanques a fin de sacar la sal y han sido dispuestas por las personas exspertas que tienen para este fin los jurados en los días que hemos pasado a visitarlos.

No obstante, el gobernador aseguraba que creía perdidos los estanques por la gran cantidad de lodo que había entrado en ellos a causa de un arroyo que arrojaba su agua descontroladamente, primero en el estanque de la sal roja y luego en el de la blanca, así como «la que entró del mar la bíspera de Santa Catalina el año pasado de [16]94. Confesando a V. Magd. que se $<\mathrm{h}>$ aumenta más esta inundación cada año y con maior abundançia el que no se saca sal».

Castellón consideró entonces que la Universidad, que debía afrontar el pago anual de unas 7.000 libras en vellón por los censos contraídos, difícilmente podría hacer frente a unos gastos como el que representaba el «desescombro» de las salinas de los muchos lodos que las ensuciaban, pero que debían esforzarse en encontrar alguna cantidad para aplicarla a la limpieza de los estanques de la sal, pues de lo contrario «ya no [h]ay qué hacer quenta de los estanques de Yviza» ${ }^{63}$.

El último gobernador de Carlos II, el catalán Domènec de la Canal, a falta de mayores inversiones en los estanques, propuso un incremento del salario de los trabajadores de las salinas, que pasarían de cobrar en vellón a hacerlo en plata. Según el gobernador, en 1699 merced a su iniciativa de pagar mejor a los operarios que extraían

62. ACA, CA, leg. 1036, jurados de Ibiza al rey, 3/XI/1695; L. Castellón al rey, 12/XI/1695 y consulta del CA, 7/XII/1695.

63. ACA, CA, leg. 1035, Lupercio Castellón a Carlos II, 20/X/1696 y respuesta del CA, 26/XI/1696. 
la sal se habían obtenido 8.000 modines (y aseguraba que la sequía que tanto había fastidiado la cosecha de grano de aquel año había favorecido la de la sal) ${ }^{64}$.

En 1700, si bien la cosecha de grano había sido muy mala -los jurados escribieron que hubo necesidad de importar 3.000 cuarteras de trigo y 500 medidas de aceite-, y a pesar de haber llovido hasta en cinco ocasiones cuando se cuajaba la sal, llegando a sacar de los estanques un palmo y medio de agua, la sal blanca se extrajo desde el día 30 de agosto y la sal roja desde el 6 de septiembre, cuando en otras ocasiones, y con menos dificultades aseguraba el gobernador De la Canal, se habían abandonado el trabajo en las salinas de Ibiza. En cualquier caso, el 24 de agosto el gobernador acudió a revisar los estanques y vio como

por unas puertas que había en una calzada que devide el estanque que no se saca del que cada año se saca entrava el cuerpo de un hombre de agua, cosa que jamás dicen se había reparado tal, y lo cierto es que los más años que se havía dejado de sacar la sal lo artribuio a este descuido, el que se [h]a reparado por este y por los benideros [...].

También explicaba que su lugarteniente en la vigilancia de los estanques, Francesc Laudes, en aquel momento estaba «executando el escombro del lodo del dicho estanque en las calzadas que no se secan para ponerlas en estado de que se puedan sacar [...]». Todo el mundo parecía estar satisfecho: los jurados creían que al final del esfuerzo se obtuvieron 7.000 modines de sal y se habían retirado muchos $\operatorname{lodos}^{65}$.

\section{EPÍLOGO Y CONCLUSIÓN}

Es notable lo que el testimonio de un mallorquín Jaume Cirer (1765-1850), quien sería enviado a Ibiza en 1786 en calidad de contador de las rentas únicas de la Corona, nos puede enseñar acerca de la dificultad para conseguir avances económicos en la España del Setecientos. Comentaba Cirer en su obra de $1803^{66}$ que la sal del llamado estanque Rojo, donde por entonces se producían 5.000 o 6.000 modines al año, cuando podría producir hasta 15.000 de limpiarse de fango, tierra e inmundicias, era la sal más selecta de la producida en la isla;

Era y es en extremo deseada de los extrangeros y especialmente de los genoveses, quienes no solamente la apetecían por su buena calidad sino también por el color roxo que creían era natural, el que se lo daban los comisionistas encargados por el comercio de Génova en el mismo Cargador o embarcadero sólo rociando de tanto en tanto con agua mezclada con tierra de las inmediaciones del mismo Cargador la sal que se iva embarcando.

Según Jaume Cirer, en 1715 el estanque Grande y el estanque del Medio o del Codolar estaban en malas condiciones de producción y la sal «que fructificaban era

64. ACA, CA, leg. 1270, gobernador de Ibiza ¿al fiscal del CA?, 3/X/1699; don Domingo de la Canal, al conde de Frigiliana, presidente del CA, y a don José de Villanueva, 16/V/1700.

65. ACA, CA, leg. 1270, Domingo de la Canal al rey, 30/IX/1700; jurados de Ibiza al rey, 10/X/1700; consulta del CA, 8/I/1701.

66. Cirer, J., Tratado de las reales salinas de Yviza y Formentera... 
de inferior calidad y por lo mismo no era apreciada y a más que como era costosísima a los trayentes tanto su saca como su conducción a los cargadores, la despreciaban y abandonaban». Otro estanque, llamado «el Borrico o el de los Burros [...] A causa de las arenas y tierra de que le llenaron las muchas aguas acaecidas en el año 1680 quedó infructífero [...)]». Según nuestro autor, entre 1770 y 1786 se gastaron 321.000 reales de vellón en limpiar los estanques ibicencos, algunos de los cuales ya necesitaban arreglos en 1803 y entre todos ellos podrían llegar a producir hasta 58.560 modines de sal ${ }^{67}$. Pero el caso es que no se producían. Como vemos, poco o nada había cambiado entre la época de los Austrias y la de los Borbones, ya que el problema de la limpieza de los estanques seguía vigente.

Como hemos analizado en las páginas precedentes, las vicisitudes climatológicas que padeció la isla de Ibiza en el transcurso del siglo XVII, sin olvidarnos, como acabamos de señalar, de la desidia de los hombres, se confabularon de tal forma que en numerosas oportunidades la crisis cerealista estuvo a punto de hundir las expectativas de futuro de la mayor de las Pitiusas. Ante las dificultades para conocer documentalmente la producción cerealícola ibicenca del Seiscientos, algunos datos que hemos podido extraer merced a la necesidad de intercambiar sal por el sustento necesario para mantener a sus habitantes nos indican que este era casi su único recurso, además del endeudamiento crónico de la Universidad, para poder sortear el infortunio. Por ello era absolutamente clave que la explotación de las salinas ibicencas fuese lo más eficiente posible, pero numerosas circunstancias, incluyendo las climáticas adversas, podían dar al traste con la producción de sal en el último momento. Los testimonios obtenidos merced a la documentación analizada, por otro lado, también admiten una lectura de la evolución climatológica de Ibiza en el transcurso del XVII, con algunas descripciones muy gráficas no sólo del trabajo de los hombres, sino también de sus dificultades para oponerse a la fuerza de la naturaleza, aunque a menudo fueron sus pequeñas y mezquinas pasiones las que perjudicaron al conjunto de la sociedad pitiusa.

67. CIRER, J., Tratado de las reales salinas de Yviza y Formentera ..., pp. 35-53. 